\title{
Correction to: Evaluation of the convective mass flux profiles associated with cumulus parameterization schemes of CMIP5 models
}

\author{
Parthasarathi Mukhopadhyay and Kumar Roy
}

Correction to: J. Earth Syst. Sci. (2020) 129:138 https://doi.org/10.1007/s12040-020-01400-5

Due to an oversight, figure 2 (Article ID 138) of the article was published with an incorrect label. The correct figure 2 is given below.
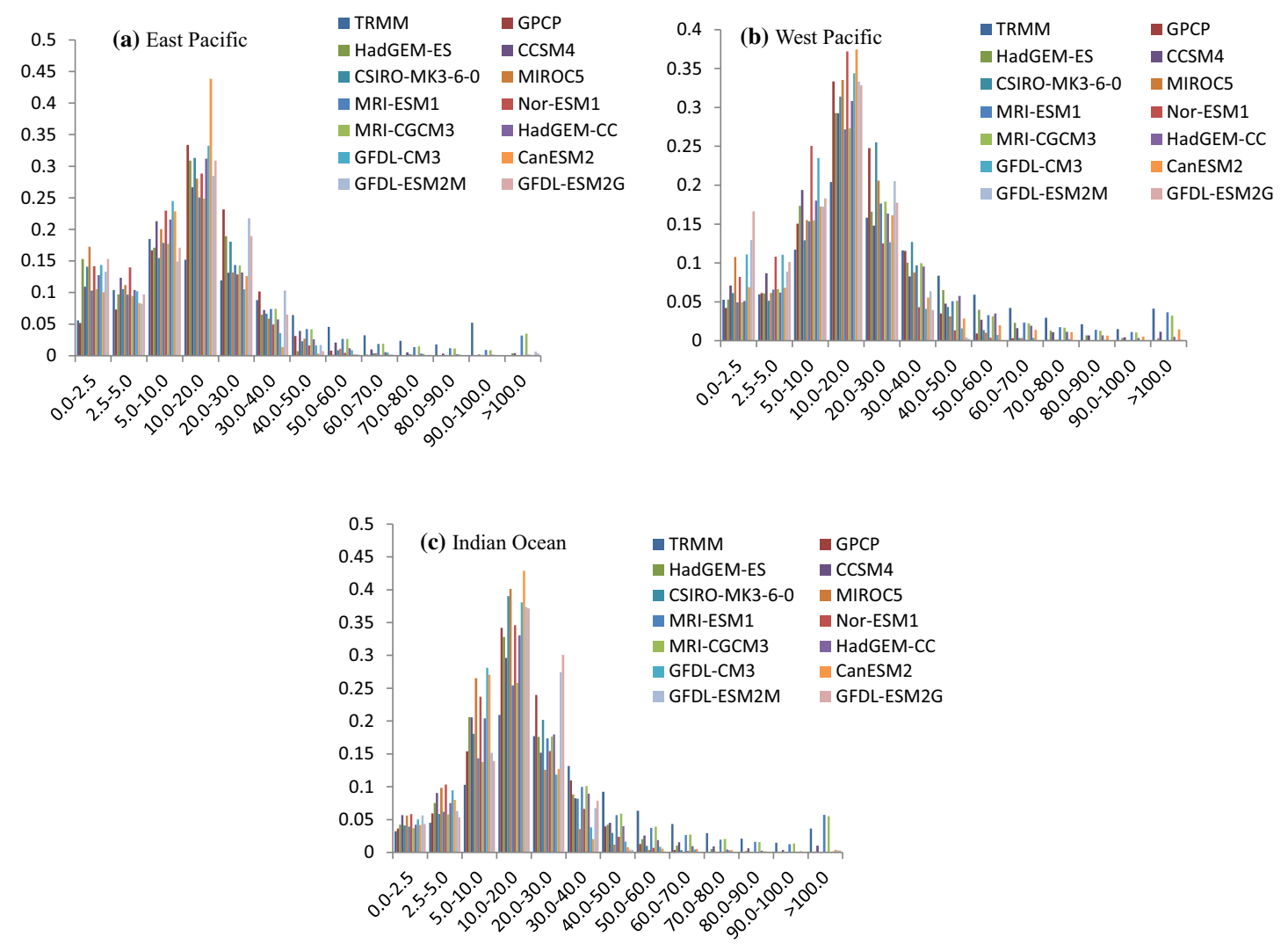

Figure 2. Rainfall PDF over East, and West Pacific, Indian Ocean from TRMM, GPCP, and CMIP5 models. The ranges of rain rate are $\left(\mathrm{mm} \mathrm{day}^{-1}\right)$ along $\mathrm{X}$ axis and rainfall $\mathrm{PDF}$ (in fraction) along $\mathrm{Y}$ axis. 